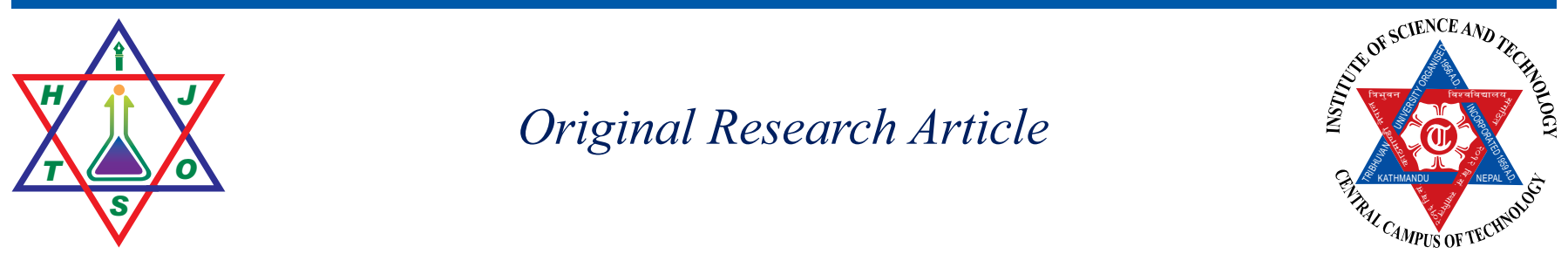

\title{
Thin Layer Drying Kinetics Modelling of Curry Leaves (Murraya koenigii L.) in Cabinet Dryer
} Arjun Ghimire $^{l^{*}}$ and Nirajan Magar ${ }^{2}$

${ }^{1}$ Department of Food Technology, Central Campus of Technology, Dharan, Sunsari, Nepal ${ }^{2}$ Dharan Multiple Campus, Dharan, Sunsari, Nepal

*Corresponding Author: Arjun Ghimire, Lecturer, Department of Food Technology, Central Campus of Technology, Dharan, Nepal E-mail: arzunghimire@gmail.com

\begin{abstract}
:
Curry leaves (Murraya koenigii L.) are the sweet smelling leaves of small tree of Rutaceae family native to Southwest Asia. In this study, the effect of temperatures $\left(50,55\right.$ and $\left.60^{\circ} \mathrm{C}\right)$ on the drying of curry leaves was investigated. The experimental data were fitted to six thin layer mathematical models (Newton, Page, Handerson and Pabis, logarithmic, two-term exponential and Midilli et al). The models were evaluated in terms of coefficient of determination $\left(\mathrm{R}^{2}\right)$, chi square $(\chi 2)$ and root mean square error (RMSE). The Midilli et al model was best fitted to the experimental data of all the models evaluated. The effective diffusivity was calculated using Fick's diffusion equation, and the value varied from $2.07 \times 10^{-12} \mathrm{~m}^{2} / \mathrm{s}$ to $2.643 \times 10^{-12} \mathrm{~m}^{2} / \mathrm{s}$. The activation energy and the diffusivity constant were found to be $21.808 \mathrm{~kJ} / \mathrm{mol}$ and $4.667 \times 10^{-8} \mathrm{~m}^{2} / \mathrm{s}$ respectively.
\end{abstract}

Keywords: Drying kinetics; Murraya koenigii; thin layer model; mathematical modelling

\section{Introduction}

Curry leaves are a popular leaf-spice used in very small quantities for their distinct aroma due to the presence of volatile oil and their ability to improve digestion. In the southern parts of India, curry leaves are mainly used to provide flavour to the curries, pickles, chutneys, soups, butter milk, south Indian sambar as well as to nonvegetarian items. In addition to food value, they add taste and smell to the foods. The leaves retain their flavour after drying and hence are marketed both in fresh and dried forms (Khatoon et al, 2011). Physical and biochemical changes that occur during drying seem to affect the quality of dehydrated product. The proper control of these reactions ensures that the dried product has a high nutritional value and a significantly extended shelf life. It is, therefore, essential to model and study the drying characteristics of food products in order to predict suitable drying conditions as part of process control and in the design and manufacture of dryers (Akonor and Amankwah, 2012). The objectives of the present research were to study the effects of temperature on the drying characteristics of curry leaves, determine a suitable thin layer mathematical model that describes its drying behaviour and evaluate the corresponding diffusivity and activation energy.

\section{Materials and Methods}

\section{Sample preparation and drying of curry leaves}

Fresh curry leaves were plucked from the different localities of Dharan sub- metropolitan city and winnowed to remove adhered dust and foreign materials. Three different lots of fresh curry leaves each weighing $50 \mathrm{~g}$ were used for drying at 50,55 and $60^{\circ} \mathrm{C}$ in a cabinet dryer till constant weight was obtained.

Drying curves were obtained by plotting moisture ratio against drying time and drying rate against free moisture content,

\section{Modelling of the drying process}

The moisture ratio was calculated using equation (1) as modified by Roberts et al., 2008:

$$
\mathrm{MR}=\frac{\mathrm{M}}{\mathrm{M}_{\mathrm{o}}} \text {. }
$$

where MR is the moisture ratio, $\mathrm{M}$ is the moisture content 
at time $t$ of the drying process ( $\mathrm{g} / \mathrm{g}$ dry solid) and $\mathrm{M}_{0}$ is the initial moisture content $(\mathrm{g} / \mathrm{g}$ dry solid). The drying curves were fitted by means of six different moisture ratio models that are widely used in most food and biological materials as shown in Table 1:

Table 1. Mathematical models applied to the drying curves

\begin{tabular}{lll} 
Model name & Mathematical Equation & References \\
\hline Newton & $M R=\exp (-\mathrm{kt})$ & Ceylan, 2007; Guine et al, 2011 \\
Page & $\mathrm{MR}=\exp \left(-\mathrm{kt}^{\mathrm{n}}\right)$ & Ceylan, 2007; Guine et al, 2011 \\
Henderson and Pabis & $\mathrm{MR}=\mathrm{a} \exp (-\mathrm{kt})$ & Ceylan, 2007; Guine et al, 2011 \\
Logarithmic & $\mathrm{MR}=\mathrm{a} \exp (-\mathrm{kt})+\mathrm{c}$ & Ceylan, 2007; Guine et al, 2011 \\
Two-Term exponential & $\mathrm{MR}=\mathrm{ae} \mathrm{e}^{-\mathrm{kt}}+(1-\mathrm{a}) \mathrm{e}^{-\mathrm{kat}}$ & Saeed et al, 2008 \\
Midilli et al. & $\mathrm{MR}=\mathrm{a} \exp \left(-\mathrm{kt}^{\mathrm{n}}\right)+\mathrm{bt}$ & Midilli et al, 2002 \\
\hline
\end{tabular}

Determination of effective moisture diffusivity and activation energy

Fick's second law of diffusion was used to evaluate the effective diffusivity of curry leaves because all of the samples showed a falling rate period in their drying

$$
\ln (\mathrm{MR})=\ln \left(8 \pi^{2}\right)-\frac{\left(-\pi^{2} \mathrm{D}_{\text {eff }}\right)}{4 \mathrm{~L}^{2}} \mathrm{t} .
$$

Where $\mathrm{D}_{\text {eff }}, \mathrm{L}$ and $\mathrm{t}$ are the effective moisture diffusivity $\left(\mathrm{m}^{2} / \mathrm{s}\right)$, thin layer thickness $(\mathrm{m})$ and time (h) respectively.

The Arrhenius equation (Equation 3) was used to

$$
\ln \left(D_{\text {eff }}\right)=\ln \left(D_{\mathrm{o}}\right)-\frac{E_{\mathrm{a}}}{R}\left(\frac{1}{T}\right)
$$

describe the relationship between the effective diffusivity and drying temperature as given by Roberts et al, (2008) by linear fitting as: diffusivity of the samples was determined by Equation 2 by linear fitting as:
Where, $D_{o}$ is the diffusivity constant $\left(\mathrm{m}^{2} / \mathrm{s}\right), \mathrm{E}_{\mathrm{a}}$ is the activation energy $\left(\mathrm{KJ} \mathrm{mol}^{-1}\right), \mathrm{R}$ is the universal gas constant $\left(8.314 \mathrm{~J} \mathrm{~mol}^{-1} \mathrm{~K}\right)$, and $\mathrm{T}$ is the absolute air temperature $(\mathrm{K})$.

Data analysis

Non- linear regression analysis was performed using Microsoft Excel 2013. The coefficient of determination
$\left(\mathrm{R}^{2}\right)$, chi- square $\left(\chi^{2}\right)$ and root mean square error (RMSE) of each mathematical model was calculated and a suitable drying model was chosen based on the goodness of fit with highest value of $\mathrm{R}^{2}$ and lowest value of RMSE and $\chi^{2}$. (Sacilik et al, 2006; Hassan-Beygi et al, 2009; Sobukola, 2009).

\section{Results and Discussion}

\section{Drying Curves}

The drying curves of curry leaves at different

temperatures are shown in Figure 1. The drying temperature significantly affected the drying rate of curry

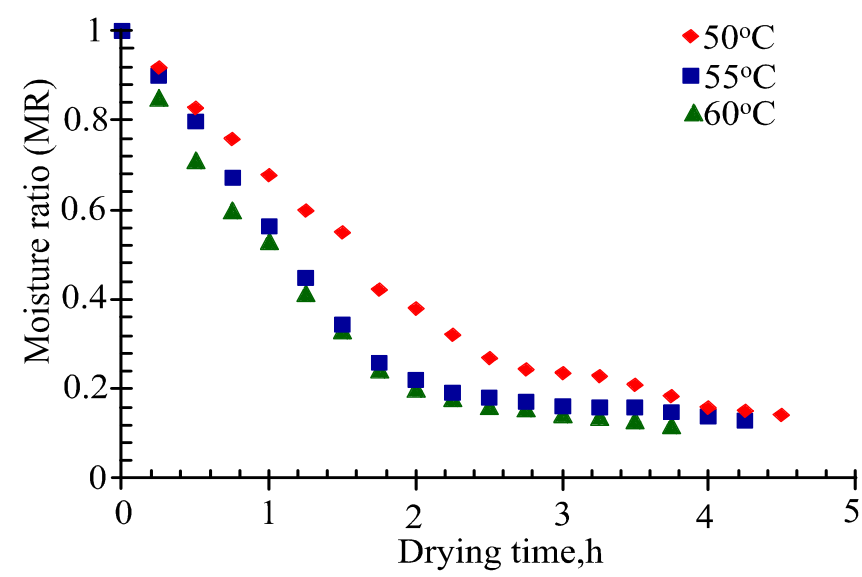

Fig 1. Drying curve of curry leaves dried at different temperatures 
leaves. This finding is in agreement with those obtained by increases, water molecules inside the sample move faster, Vega-Galvez et al, (2012), who studied the effect of which increases the distance between molecules and temperature and air velocity on the drying kinetics of apple hence, reduces the attractive forces between them. Thus, slices, and found that the drying rate of apples increased an increase in the drying temperature increases the amount with increase in temperature. At high drying temperatures, of moisture removed from the samples.

the drying rate is faster due to the excitation of molecules in the samples (Jamali et al, 2006). As the temperature

From Figure 2, it was clear that drying rate of curry leaves the surface of product disappears and hence falling rate falls in falling rate period. That means, critical moisture starts. content was not found on the drying rate curve. The drying Mathematical modelling rate was decreased and less moisture was available at the The moisture ratio (MR) was calculated using Equation surface to evaporate. The food surface is no longer 1, and regression analysis was performed using saturated with moisture. That means, a layer of water on Microsoft Excel.

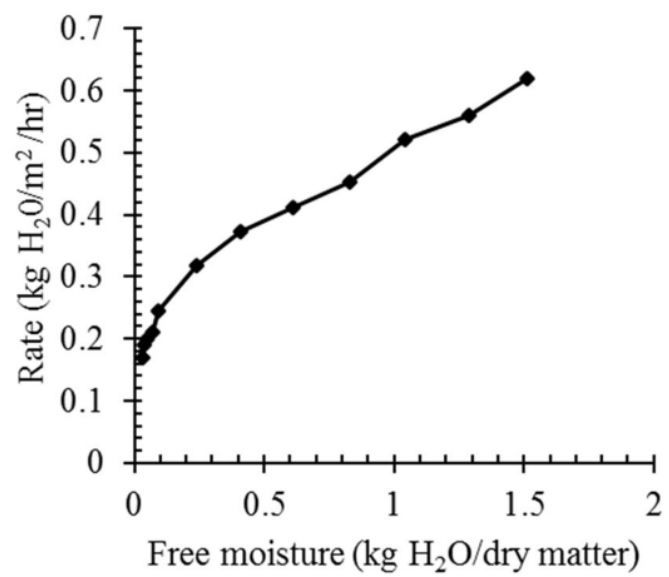

Fig 2. Drying rate curve of curry leaves showing drying rate as a function of moisture content

Table 2 shows the calculated data for the selected thin layer were confirmed by plotting the graph of the experimental drying model. Compared to other mathematical models, MR versus the predicted MR (Figure 3). All of the $\mathrm{R}^{2}$ the Midilli et al, model was the best model for all of the values were greater than 0.99 , which indicates that the fit drying temperatures because the lowest RMSE and $\chi^{2}$ was good were observed with highest $\mathrm{R}^{2}$ values (Table 3 ). The results

Table 2. Mathematical drying model constants

\begin{tabular}{cll}
\hline $\mathrm{T}\left({ }^{\circ} \mathrm{C}\right)$ & Model name & Model constants \\
\hline & Newton & $\mathrm{k}=0.461072$ \\
50 & Page & $\mathrm{n}=1.09307, \mathrm{k}=0.428526$ \\
& Logarithmic & $\mathrm{a}=1.028256, \mathrm{c}=0.011335, \mathrm{k}=0.492751$ \\
& Two-term exponential & $\mathrm{a}=1.000001, \mathrm{k}=0.456173$ \\
& Midilli et al. & $\mathrm{a}=0.990611, \mathrm{n}=1.322927, \mathrm{k}=0.43904, \mathrm{~b}=0.025242$ \\
\hline \multirow{3}{*}{55} & Newton & $\mathrm{k}=0.62596$ \\
& Page & $\mathrm{n}=1.029234, \mathrm{k}=0.616132$ \\
& Logarithmic & $\mathrm{a}=0.9905, \mathrm{c}=0.0738, \mathrm{k}=0.7995$ \\
& Two-term exponential & $\mathrm{a}=1.0000001, \mathrm{k}=0.62596$ \\
& Midilli et al. & $\mathrm{a}=0.993631, \mathrm{n}=1.437336, \mathrm{k}=0.666903, \mathrm{~b}=0.03571$ \\
\hline \multirow{3}{*}{60} & Newton & $\mathrm{k}=0.700233$ \\
& Page & $\mathrm{n}=0.98835, \mathrm{k}=0.703983$ \\
& Logarithmic & $\mathrm{a}=0.971249, \mathrm{c}=0.053422, \mathrm{k}=0.816247$ \\
& Two-term exponential & $\mathrm{a}=1, \mathrm{k}=0.700233$ \\
& Midilli et al. & $\mathrm{a}=0.98748, \mathrm{n}=1.211065, \mathrm{k}=0.758577, \mathrm{~b}=0.026085$ \\
\hline
\end{tabular}




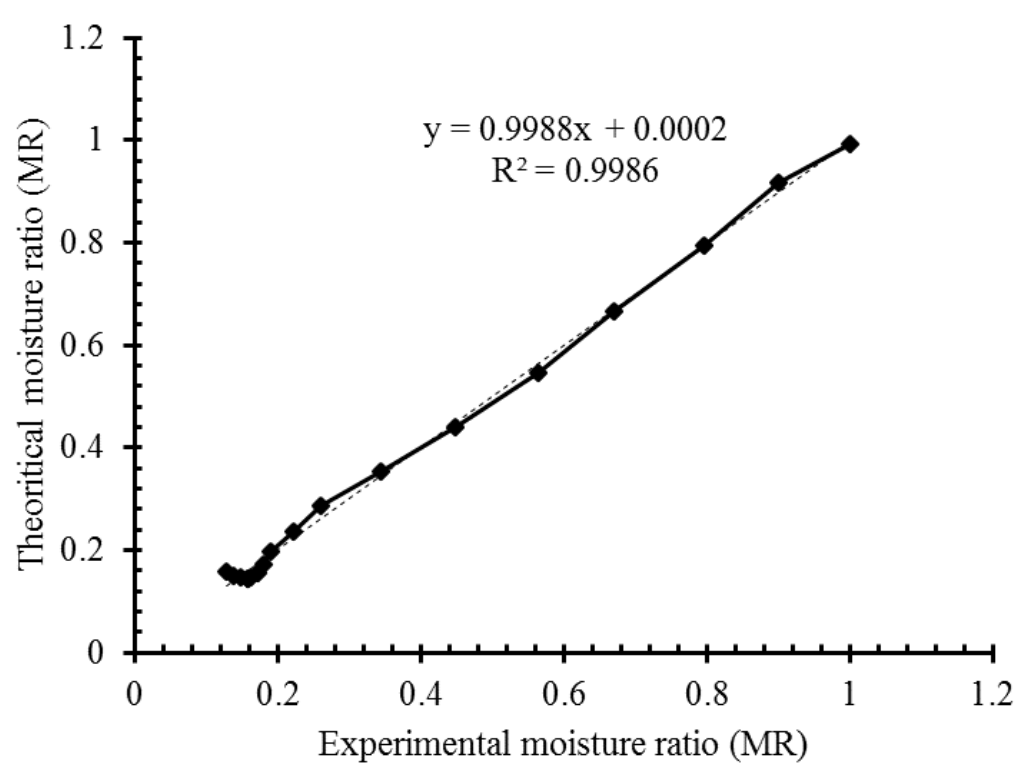

Fig.3. Calculated MR vs actual MR for the Midilli et al. model at $55^{\circ} \mathrm{C}$

Table 3. Statistical results for thin layer mathematical modelling at different drying temperatures

\begin{tabular}{|c|c|c|c|c|}
\hline $\mathrm{T}\left({ }^{\circ} \mathrm{C}\right)$ & Model name & RMSE & $\mathrm{X}^{2}$ & $\mathrm{R}^{2}$ \\
\hline \multirow{5}{*}{50} & Newton & 0.029632 & 0.000927 & 0.9954 \\
\hline & Page & 0.02518 & 0.0007 & 0.9960 \\
\hline & Logarithmic & 0.026454 & 0.0008 & 0.9953 \\
\hline & Two-term exponential & 0.0294 & 0.0009 & 0.9953 \\
\hline & Midilli et al. & 0.0168 & 0.0003 & 0.9980 \\
\hline \multirow{5}{*}{55} & Newton & 0.045597 & 0.002 & 0.987343 \\
\hline & Page & 0.045365 & 0.002315 & 0.9875 \\
\hline & Logarithmic & 0.0374 & 0.0084 & 0.991 \\
\hline & Two-term exponential & 0.045597 & 0.00233 & 0.98734 \\
\hline & Midilli et al. & 0.01445 & 0.00094 & 0.9986 \\
\hline \multirow{5}{*}{60} & Newton & 0.028641 & 0.000875 & 0.9947 \\
\hline & Page & 0.02858 & 0.000934 & 0.994754 \\
\hline & Logarithmic & 0.0243 & 0.00073 & 0.9968 \\
\hline & Two-term exponential & 0.028641 & 0.000937 & 0.99478 \\
\hline & Midilli et al. & 0.016042 & 0.000343 & 0.999269 \\
\hline
\end{tabular}

Effective Diffusivity $\left(\mathbf{D}_{\text {eff }}\right)$ and Activation energy $\left(\mathbf{E}_{\mathrm{a}}\right) \quad$ results were calculated using equation $(2)$ and found to be As the drying temperature increased, the value of effective within the range of effective diffusivities of agriculture diffusivity also increased. Samples dried at $50{ }^{\circ} \mathrm{C}$ products reported by several researchers (Table 4). presented the lowest $\mathrm{D}_{\text {eff }}$, which was $2.07 \times 10^{-12} \mathrm{~m}^{2} / \mathrm{s}$. These

Table 4. Effective diffusivities of dried curry leaves and other agriculture products.

\begin{tabular}{lll} 
Agriculture Material & Effective Diffusivity, $\mathrm{D}_{\text {eff }}\left(\mathrm{m}^{2} / \mathrm{s}\right)$ & References \\
\hline Curry leaves $\left(50^{\circ} \mathrm{C}\right)$ & $2.07 \times 10^{-12}$ & Current work \\
Curry leaves $\left(55^{\circ} \mathrm{C}\right)$ & $2.233 \times 10^{-12}$ & Current work \\
Curry leaves $\left(60^{\circ} \mathrm{C}\right)$ & $2.643 \times 10^{-12}$ & Current work \\
Apple & $0.483 \times 10^{-10}-2.019 \times 10^{-10}$ & Kaya et al., 2007 \\
Celery & $3.43 \times 10^{-11}-1.714 \times 10^{-10}$ & Evin, 2012 \\
Cocoa & $8.01 \times 10^{-11}-4.84 \times 10^{-10}$ & Hii et al., 2009 \\
\hline
\end{tabular}


The estimated diffusivity constant, $\mathrm{D}_{0}$, and activation energy, $E_{a}$, were $4.667 \times 10^{-8} \mathrm{~m}^{2} / \mathrm{s}$ and $21.808 \mathrm{~kJ} / \mathrm{mol}$, respectively. These values were determined using the relationship shown in Figure 4. The value of $E_{a}$ was within the range of values reported in previous studies, which varied from $12.32 \mathrm{~kJ} / \mathrm{mol}$ to $51.26 \mathrm{~kJ} / \mathrm{mol}$ (Hii et al, 2009; Senadeera et al, 2003).

$1 / \mathrm{T}$

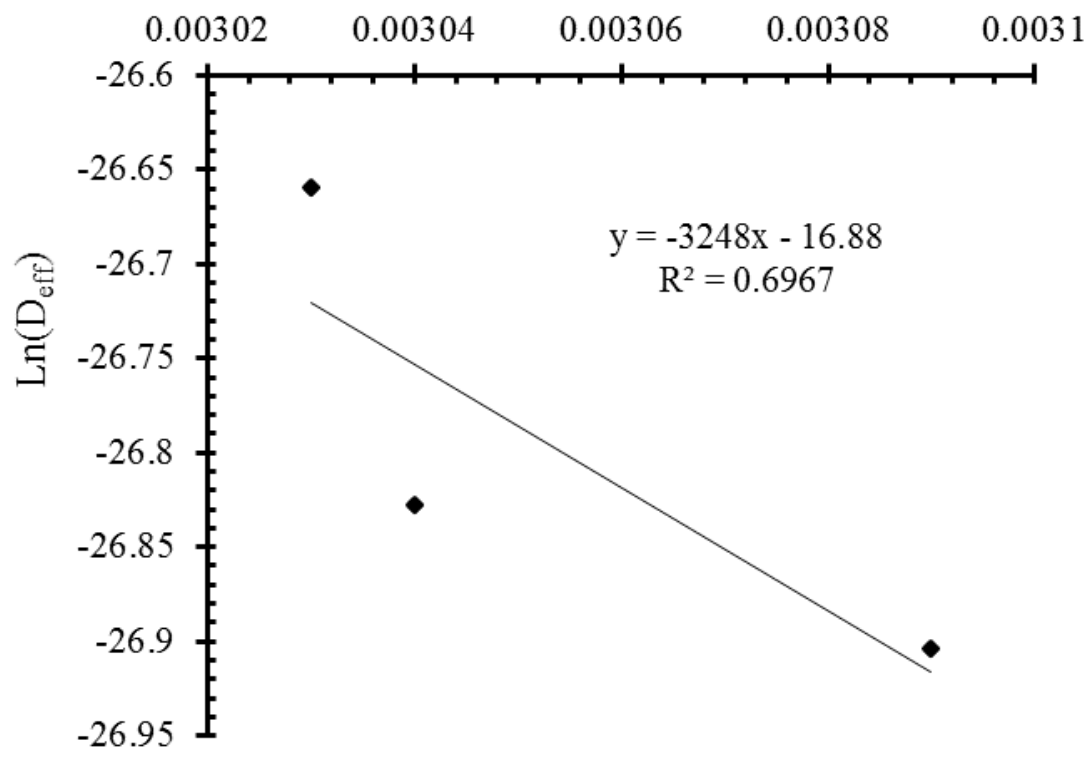

Fig 4: Plot of $\ln \mathrm{D}_{\text {eff }}$ Vs. $1 /$ T during the cabinet drying of curry leaves

\section{Conclusion}

The drying of curry leaves was carried out at three different drying temperatures $\left(50,55\right.$ and $\left.60{ }^{\circ} \mathrm{C}\right)$ in a cabinet dryer. Based on the present results, the drying temperature significantly affected the drying rate of curry leaves. According to the R2, $\chi 2$, and RMSE values, the Midilli et al. model was best fitted to the experimental data. The effective diffusivities varied from $2.07 \times 10^{-12}$ $\mathrm{m}^{2} / \mathrm{s}$ to $2.64 \times 10^{-12} \mathrm{~m}^{2} / \mathrm{s}$. The diffusivity constant and activation energy were estimated using the Arrhenius equation, and the values were found to be $4.667 \times 10-8$ $\mathrm{m}^{2} / \mathrm{s}$ and $21.808 \mathrm{~kJ} / \mathrm{mol}$ respectively.

\section{References}

Akonor PT and Amankwah EA (2012). Thin layer drying of solar-dried Amaranthus hybridus and Xanthosoma sagittifolium leaves. J. of food technology. 10, 92-6.

Ceylan I, Aktas M, \& Dogan H . Mathematical Modelling of Drying characteristics of tropical fruits. Applied Thermal Engineering, 2007, 27, 1931-6.

Evin D. Thin layer drying kinetics of Gundelia tournefortii L. Food and Bioproducts Processing, 2012, 90(2), 323-32.

Guine RPF, Pinho S and Barroca MJ. Study of the convective drying of pumpkin (Cucurbita maxima). Food and Bioproducts Processing, 2011, 89(4), 4228.

Hassan-Beygi SR, Aghbashlo M, Kianmehr MH and
Massa, J. Drying characteristics of walnut (Juglans regia $\mathrm{L}$.) during convection drying. International Agrophysics, 2009, 23: 129-35.

Hii CL, Law CL, Cloke M and Suzannah S. Thin layer drying kinetics of cocoa and dried product quality. Biosystems Engineering, 2009, 102(2), 153-61.

Jamali A, Kouhila M, Mohamed LA, Jaouhari J, Idlimam, A, and Abdenouri N. Sorption isotherms of Chenopodium ambrosioides leaves at three temperatures. Journal of Food Engineering, 2007 72(1), 77-84.

Kaya A, Aydin O, \& Demirtas C. Drying Kinetics of Red Delicious Apple. Biosystem Engineering, 2007, 96(4), 517-24.

Khatoon J, Verma A, Chacko N and Sheikh S. Utilization 
of dehydrated curry leaves in different food products Indian J Natural Products Resources. 2011, 2 (4), 508-11.

Midilli A, Kucuk H and Yapar Z. A new model for singlelayer drying. Drying technology, 2002, 20(7), 150313.

Roberts JS, Kidd DR and Padilla-Zakour O. Drying kinetics of grape seeds. Journal of Food Engineering, 2008, 89(4), pp.460-5.

Sacilik K, Elicin AK and Unal G. Drying kinetics of uryani plum in a convective hot-air dryer. Journal of Food Engineering, 2006, 76: 362-8.

Saeed I, Sopian K, and Abidin ZZ. Drying characteristics of roselle (1): mathematical modeling and drying experiments. Agricultural Engineering International: CIGR Journal. 2008.

Senadeera W, Bhandari BR, Young G and Wijesinghe B.
Influence of shapes of selected vegetable materials on drying kinetics during fluidized bed drying. Journal of Food Engineering, 2003, 58(3), 277-83.

Sobukola O. Effect of pre-treatment on the drying characteristics and kinetics of okra (Abelmoschus esculetus (L.) Moench) slices. International Journal of Food Engineering, 2009, 5(2) (Article 9)

Vega-Galvez A, Ah-Hen K, Chacana M, Vergara J, Martínez-Monzo J, Garcia-Segovia P, Di Scala K. Effect of temperature and air velocity on drying kinetics, antioxidant capacity, total phenolic content, color, texture and microstructure of apple (var. Granny Smith) slices. Food Chemistry, 2012, 132(1), 51-9. 